\title{
Comparative Study between Treatment of Lumbar Disc Herniation with Intra Discal Ozone and Transforaminal Steroid Injection versus Steroid Injection only
}

\author{
Abd El Shafy Ahmed Haseeb, Abd El Hameed Abd El Hares, Khaled Mohamed Abd El Moez, \\ Ashraf Ismail Mustafa, and Osama Eid Ahmed Ahmed*
Department of Physical Medicine, Rheumatology and Rehabilitation, Faculty of Medicine, Al- Azhar University

*Corresponding author: Osama Eid Ahmed Ahmed, Mobile: (020)01274858137, E-Mail: osmaead@gmail.com

\begin{abstract}
Background: Oxygen-ozone therapy is a minimally invasive treatment for lumbar disc herniation that exploits the biochemical properties of a gas mixture of oxygen and ozone.

Objective: The purpose of our study was to prospectively evaluate the clinical effectiveness of oxygenozone therapy and compared the therapeutic outcome of injection of oxygen-ozone combined steroid with injection of steroid alone at different follow-up period.

Patients and Methods: One hundred patients were included for this study from al-Agouza Physical Medicine, Rheumatology and Rehabilitation center. From March 2014 to April 2016, we treated 100 patients (42 men, 58 women; age range, 23-65 years) with lumbar disk herniation (L3-4, 23 patients; L4-5, 61 patients; L5-S1, 75 patients) and radicular pain. The mean duration of radicular pain at the time of treatment was 8 weeks.

Result: Satisfactory clinical outcomes were obtained in both groups after two weeks, three months and at 6 months. Treatment was successful in patients in group I and patients in group II. The difference between group I and group II was insignificant.

Conclusion: $\mathrm{O} 2-\mathrm{O} 3$ seems to play a role in pain relief, and we suggest the administration of the $\mathrm{O} 2-$ $\mathrm{O} 3$ mixture combined with transforaminal steroid injection as a first-choice treatment before recourse to surgery or when surgery is not possible.
\end{abstract}

Keywords: Lumbar Disc Herniation, Intra Discal Ozone, Transforaminal Steroid, Steroid Injection

\section{Introduction}

The lumbosacral region is a critical area in the spinal column subjected to forces greater than elsewhere in the body with an acute change in the direction of transmission of forces at this level. Low back pain (LBP) is one of the most common complaints that a patient presents with at a pain clinic. It has been an important clinical, social, economic, and public health problem affecting the human population worldwide ${ }^{(1)}$.

Ozone-oxygen nucleolysis is one of the treatments for patients with subacute and chronic low back pain that needs careful evaluation with respect to its effectiveness in short-and long-term pain relief. Ozone-oxygen nucleolysis is a minimally invasive therapy for the treatment of disk herniations and is often combined with periradicular administration of steroids and local anesthesia ${ }^{(2)}$. The treatment is based on various mechanisms of action. Ozone (i.e., O3) is an unstable, strongly oxidizing gas with antiseptic, immunomodulating, and analgesic and antiinflammatory characteristics ${ }^{(3)}$.

Intradiscal ozone has a direct effect on proteolysis during the release of water molecules and cell degeneration of the matrix, which is replaced by connective tissue and blood cells ${ }^{(4)}$. The resulting effect on the disk nucleus is mainly a result of the dehydration of the fibrillary matrix of the nucleus pulposus, revealing collagen fibers and signs of regression like vacuole formation and fragmentation. The reduction in herniated disk volume is one of the therapeutic aims of intradiscal administration of medical ozone, as disk shrinkage may reduce nerve root compression. Several previous studies addressed the subject of volume changes in test animals such as pigs, dogs, and rabbits ${ }^{(5)}$.

Previously published studies have shown an association between the reduction of the herniated lumbar disk size and the improvement in patient symptoms with reduction in nerve root edema. It has been 
reported a clinical improvement in a group of patients who showed a statistically significant reduction in the volume of the herniated disk portion. In addition, published studies on humans have mentioned a volume reduction after ozone-oxygen injection. Still, none of the studies performed in humans provided a quantitative assessment of lumbar disk volume changes after ozone-oxygen nucleolysis. In addition, none of the published studies attempted to correlate the disk volume changes after ozone-oxygen injection with the patient's age, sex, or initial disk volume ${ }^{(\boldsymbol{(})}$.

Aim of the work:

The aim of this study is to prospectively compare the clinical effectiveness of intraforaminal and intradiscal injections of a mixture of a steroid, a local anesthetic, and oxygen-ozone (O2-O3) (chemodiscolysis) versus intraforaminal and intradiscal injections of a steroid and an anesthetic in the management of radicular pain related to acute lumbar disc herniation.

\section{Patients and Methods Patients}

One hundred patients were included for this study from al-Agouza Physical Medicine, Rheumatology and Rehabilitation center.

From March 2014 to April 2016, we treated 100 patients (42men, 58 women; age range, 23-65 years) with lumbar disc herniation (L3-4, 23 patients; L4-5, 61 patients; L5-S1, 75 patients) and radicular pain. The mean duration of radicular pain at the time of treatment was 8 weeks; we obtained informed consent from all patients.

\section{Inclusion criteria}

- Comprised monoradicular pain.

- Lumbar disc herniationon MR images; Radiological criteria: Protrusion, contained disc, with or without signs of disc degeneration, herniation site congruous with the neurologic level, and ODI greater than $30 \%$.

- All patients complained of pain for at least 8 weeks.

- They had received conservative therapy (physiotherapy and/or non steroidal anti-inflammatory drugs and/or intramuscular steroids) for 2-4 weeks, with no or poor clinical improvement.

\section{Exclusion criteria}

- Comprised pregnancy

- Allergy to proposed drugs.

- Major neurologic deficits.

- Patients who had clinically diagnosed syndromes that are able to mimic the symptoms of a lumbar disc herniation: facet syndrome, sacroileitis, bone lesions (infective, inflammatory, or neoplastic).

- Previous spine surgery.

- Radiculitis secondary to spinal stenosis, either foraminal or central.

- Radiculitis without disc herniation; and patients with bilateral radiculitis.

- Patients with uncontrolled medical illnesses, unstable psychiatric disorders, extremely high dose opioid users not amenable to reductions, and those with an inability to participate in outcomes assessments.

- Pregnant and lactating women and patients with a history of potential for any type of adverse reactions to steroids or local anesthetics.

- Sequestrated disc contents.

- Involvement of more than two discs.

- History of G6PD deficiency in patients who were candidates to receive intradiscal ozone injection.

- Hemorrhagic diathesis.

- Suspected spondylodiscitis.

\section{Pre-Enrollment Evaluation}

Demographic data, medical and surgical histories, and co-existing disorders were recorded. All patients underwent a physical examination. Functional assessment using the ODI (ODI) was independently performed by the nurse assessing the patient prior to the enrollment in the trial. Radiologic findings showing disc herniation based on magnetic resonance imaging (MRI) were taken into Consideration. Work status and opioid intake over the year prior to enrollment were also assessed.

Electrodiagnostic studies: For lumbar radiculopathy evaluation, include nerve conduction studies, H-reflex and needle electromyography including spontaneous activity abnormalities and voluntary motor unit action potential abnormalities. performed
Preliminary clinical evaluation was 
The level to be treated was chosen on the basis of results from a neurologic examination, correspondence between imaging and clinical findings. The 100 enrolled patients were all the ones who met our criteria and who were treated during the study time.

The patients were randomly assigned to one of three groups (A, B and C) by means of a randomization grid.

Group A (I): included 40 (patients 17 men and 23 women; mean age, 43 years) Group I underwent intraforaminal and intradiscal injections of $2 \mathrm{~mL}$ of triamcinolone acetonide (40 $\mathrm{mg} / \mathrm{mL}$ Kenacort), with $1 \mathrm{~mL}$ injected in the epidural space and $1 \mathrm{~mL}$ injected inside the disc, and $2-4 \mathrm{~mL}$ of $2 \%$ ropivacaine.

Group B (II): included 40 patients (17 men and 23 women; mean age, 41 years). Group II received the same treatment with the addition of an $\mathrm{O} 2-\mathrm{O} 3$ mixture, with an ozone concentration of $28 \mathrm{~g} / \mathrm{mL}$. We injected $5-7 \mathrm{~mL}$ of O2-O3 at intraforaminal level (mean, 6.5 $\mathrm{mL})$ and $5-7 \mathrm{~mL}$ of $\mathrm{O} 2-\mathrm{O} 3$ inside the disc (mean, $5.8 \mathrm{~mL}$ ). Patients were blinded as to whether they had received $\mathrm{O} 2-\mathrm{O} 3$ as part of the treatment.

Group C (III): included (20 patients; 8 men and 12 women mean age: 41). Patients were treated with $1.5 \mathrm{~mL}$ of preservative-free lidocaine $1 \%$, followed by a $0.5 \mathrm{~mL}$ sodium chloride solution

\section{Methods}

The procedures were always performed on an outpatient setting. All patients were treated in a sterile operating room in an ambulatory surgery center. The procedures were performed by one physician using appropriate monitoring. Before every procedure, the patients received premedication with intravenously administered $1 \mathrm{~g}$ of cefazoline, $30 \mathrm{mg}$ of ketorolac, and $50 \mathrm{mg}$ of ranitidine. arm guidance.

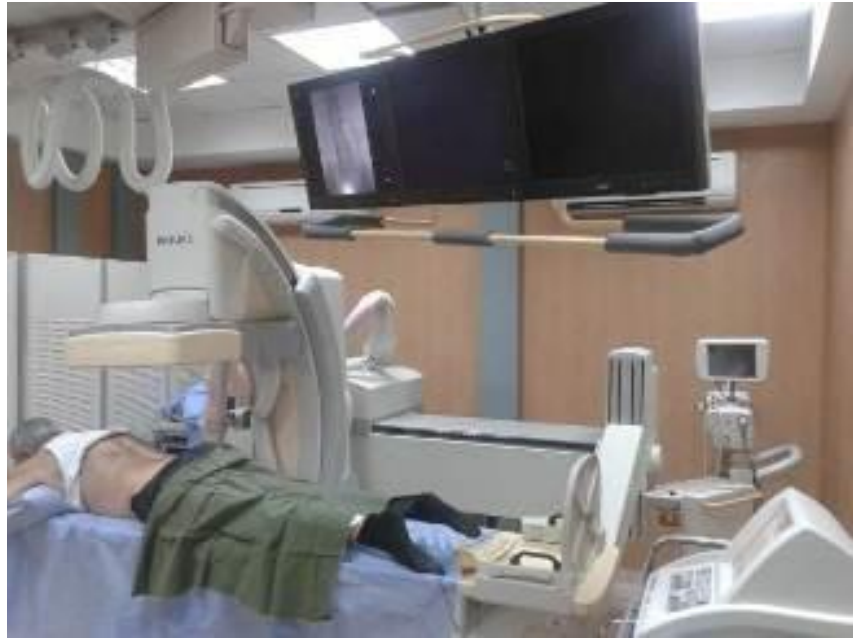

Figure (1): Real time injection with C-arm Guidance.

Group A Injection together within filtration of steroid xylocaine mixture on to the herniated disc and along the inflamed nerve root. Access to the disc herniation site was achieved by employing a posterolateral extrapedicular approach on the symptomatic side using an 18-gauge spinal needle. This approach is similar to that used for standard lumbar discography.

The patient is put in prone position on a radiolucent frame. Under fluoroscopic guidance, the target site was located and the entry site was marked on the skin at a point between $8 \mathrm{~cm}$ and $12 \mathrm{~cm}$ from the midline. After sterile preparation, draping, and local anesthesia, the spinal needle was inserted directly into the triangular working zone as described by Kambin (Figure 2) ${ }^{(7)}$.

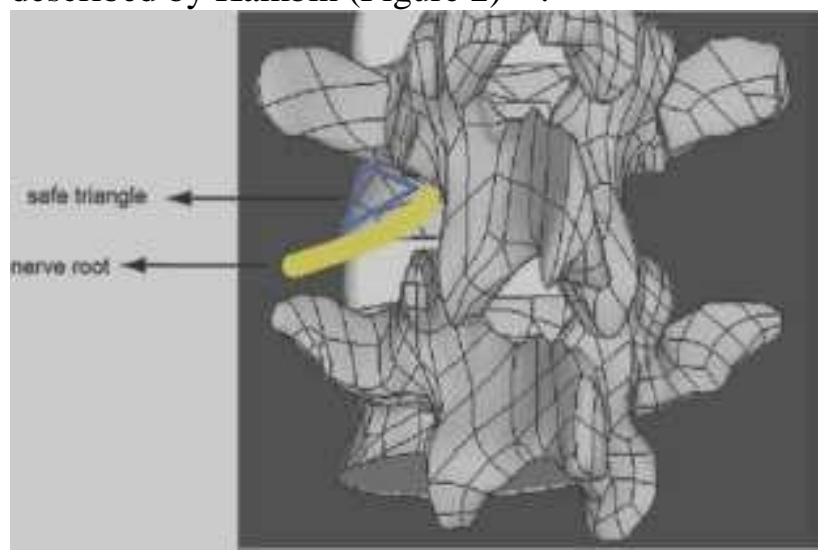

Figure (2): Kambin's triangle ${ }^{(7)}$.

Both anteroposterior and lateral

fluoroscopic projections confirmed the proper needle position. Once the tip of the needle was placed on the outer surface of the annulus fibrosus, $1 \mathrm{ml}$ to $2 \mathrm{ml}$ of Isovist-300 (Schering AG, Berlin, Germany) was injected to visualize 
the posterior annular boundary and the corresponding nerve root (Figure3).

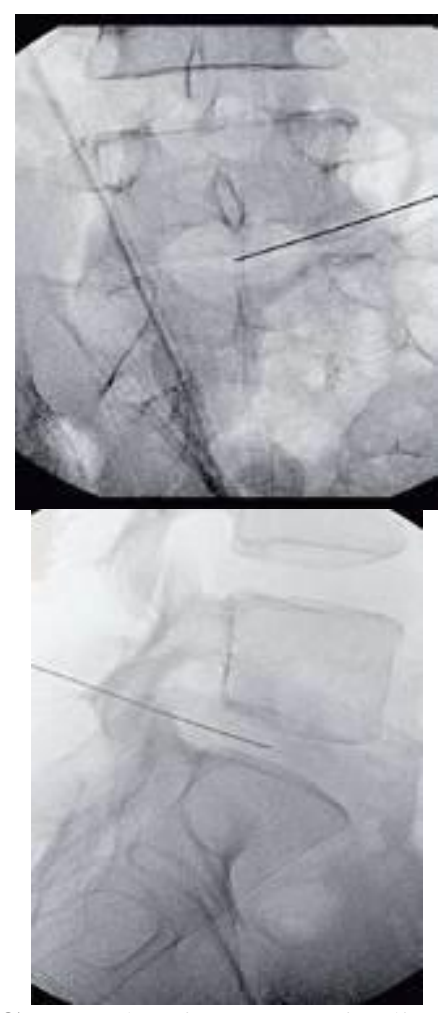

Figure (3): Lumbar intersomatic disc puncture fluoroscopy guided, real study's picture.

After an adequate flow of contrast medium to the target area had occurred and no blood or cerebrospinal fluid was aspirated, $1 \mathrm{ml}$ of betamethasone acetate mixed with $1 \mathrm{ml} \mathrm{1 \%}$ xylocaine was injected.

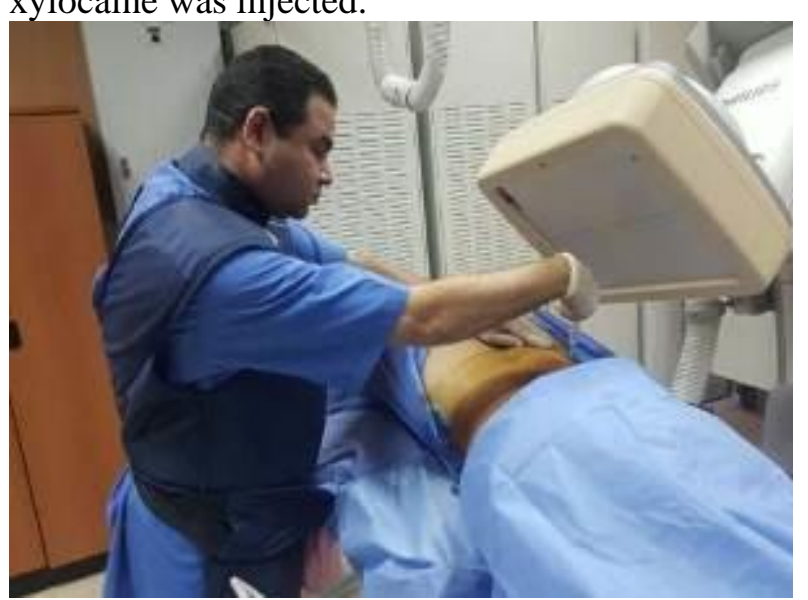

Figure (4): Injection of local anaestheic.

Spinal needles were directed under intermittent fluoroscopic guidance into the neural foramens such that the tip rested within the triangle composed of the nerve root medially, the bony pedicle superiorly, and the lateral border of the foramen laterally. The needle positions were confirmed by observing the flow of $1 \mathrm{~mL}$ ofiohexol 180 contrast medium injected at each level. One milliliter of $40 \mathrm{mg} / \mathrm{mL}$ triamcinolonediacetate mixed with 1 $\mathrm{mL}$ of $0.25 \%$ bupivacaine for a total of $2 \mathrm{~mL}$ was injected at each level with a total inject at a volume of $4 \mathrm{~mL}$.

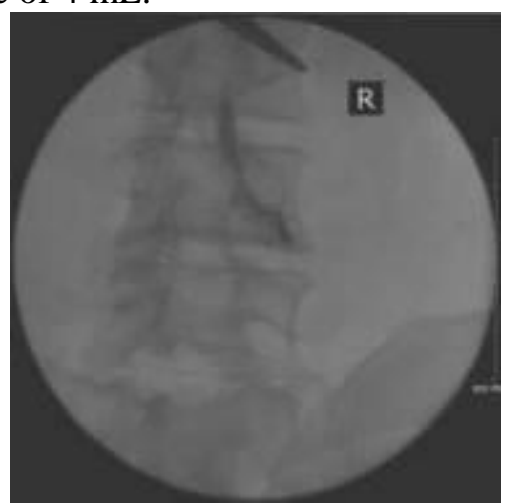

Figure (5): Classic transforaminal epidural steroid injection at L4-5. An oblique radiograph shows that contrast material has spread to L4-5 disc, real study's picture.

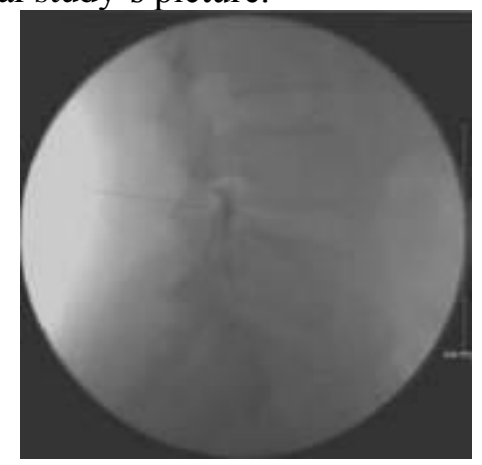

Figure (6): A lateral spot radiograph shows the needle tip in the posterior aspect of the L4-5 disc space.

Group B received the same treatment as group A with the addition of an $\mathrm{O} 2-\mathrm{O} 3$ mixture. The procedure was performed under $\mathrm{C}$-arm guidance. With the patient in the prone position; the puncture point was selected at the lesion disc level, 8 to $12 \mathrm{~cm}$ from the midline. After local anesthesia of $2 \%$ lidocaine, the 21gange multi-hole needle was directed towards the center of the disc through the posterolateral approach. When the needle tip was determined radiographically in the right position, $10 \mathrm{ml}$ oxygen-ozone mixture $(25-30 \mu \mathrm{g} / \mathrm{ml})$ was extracted from the ozone generator (ozone line E80, Italy) and was injected into the disc in 15 seconds.

In patients with ruptured annulus, the injection resistance will be low and the gas column can be seen in the epidural space and 1 
$\mathrm{mL}$ injected inside the disc space, and in the patients with contained disc herniation, the injection resistance may be high and there may be some difficulties in injecting the gas into disc.

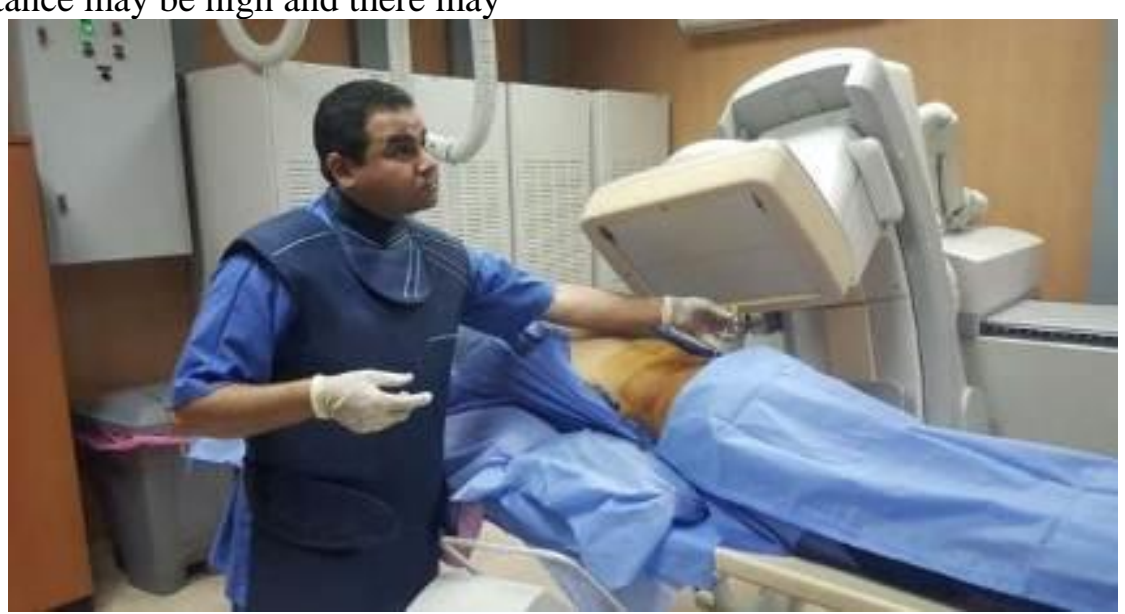

Figure (7): Adjustment of the needle under fluoroscopic guidance.

We always push the needle forth and back repeatedly to get the fully contacting of the ozone and nucleus for the purpose of satisfied oxidating. After the injection in disc space, we draw the needle to the epidural space where the needle tip should lie to the middle point of intervertebral foramen in lateral view and lie to the inner margin of pedicle in anteroposterior view.

After the needle was determined radiographically, to be in the appropriate position, we inject $10 \mathrm{ml} \mathrm{O} 2-\mathrm{O} 3$ mixture into the foramen space. The gas can be seen diffused into the intervertebral foramen.
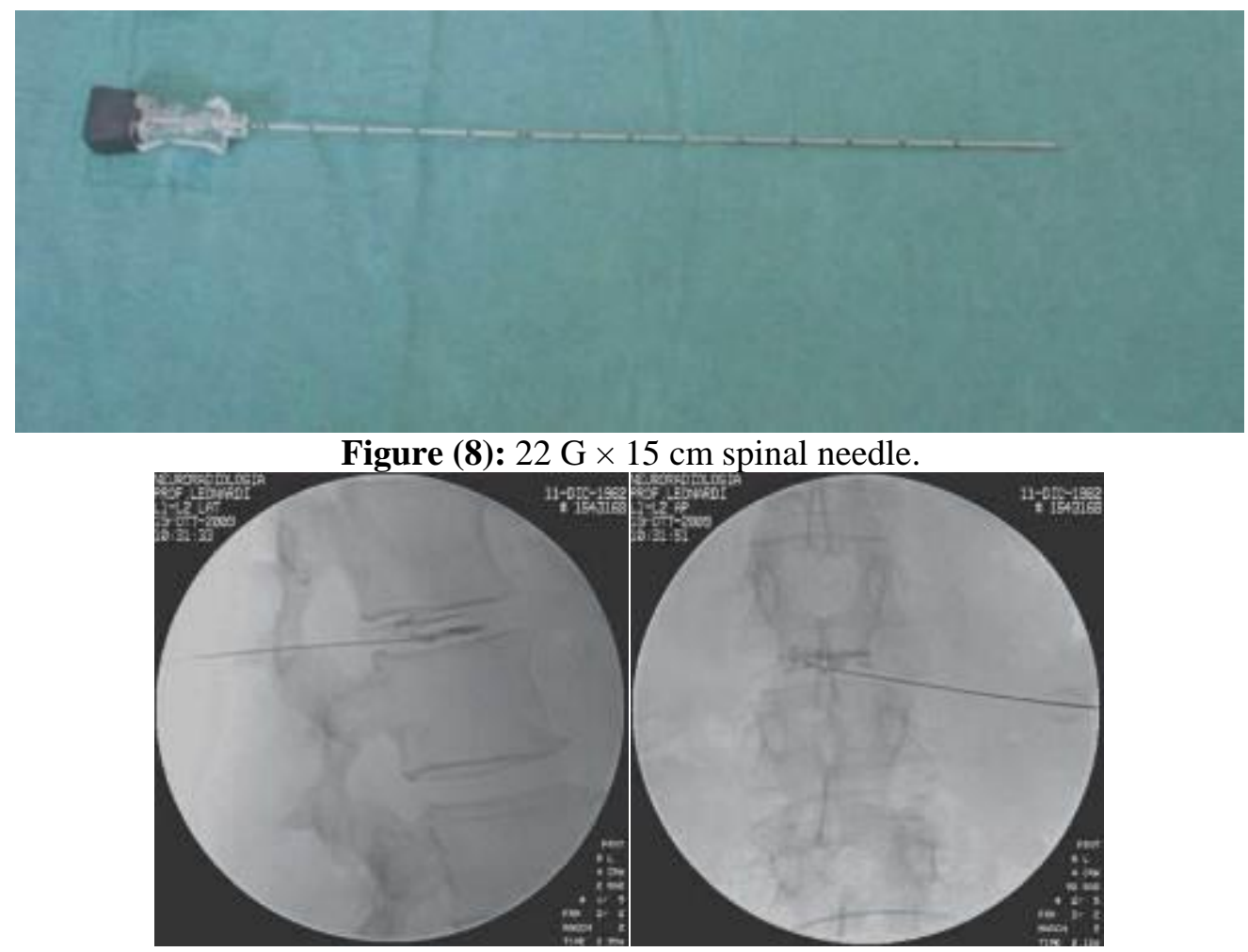

Figure (9): Oblique and anteroposterior view indicating intradiscal position of the needle, real study's picture. 


\section{Outcome Evaluation}

Finally, patients were monitored for 6 hours in the recovery room before they were discharged. The patients were trained to record the pain score, functional disability and any possible complications or limitations. The follow-upper iodine both groups was considered 6 months and the pain level was evaluated based on the visual analogue scale and ODI (ODI).

VAS was measured by a $10 \mathrm{~cm}$ length horizontal bar, so that the patient would indicate his/her pain on the axis from zero to 10 $\mathrm{cm}$. The measured interval times were before intervention and 2 weeks, 3, 6 months after performing the intervention. The investigator called the patients and asked them for followup visits. All data were recorded in questionnaire forms. Other demographic information and any possible complications were recorded based on the questionnaire.

To determine the effectiveness of the procedures, a 6-month follow-up was performed. We administered the Oswestry Low Back Pain Disability Questionnaire ${ }^{(8)}$ to all patients the day of the procedure, 2 weeks later and 3 and 6 months later.

\section{Interpretation of scores:}

1- $0 \%$ to 20\%: minimal disability: The patient can cope with most living activities. Usually no treatment is indicated a part from advice on lifting sitting and exercise.

2- 21\%-40\%: moderate disability: The patient experiences more pain and difficulty with sitting, lifting and standing. Travel and social life are more difficult and they may be disabled from work. Personal care, sexual activity and sleeping are not grossly affected and the patient can usually be managed by conservative means.

3-41\%-60\%: severe disability: Pain remains the main problem in this group but activities of daily living are affected. These patients require a detailed investigation.

4- 61\%-80\%: crippled: Back pain impinges on all aspects of the patient's life. Positive intervention is required.

5- 81\%-100\%: These patients are either bedbound or exaggerating their symptoms.
The Oswestry is commonly accessible as a one page questionnaire which can be preceded and completed simply in a few minutes ${ }^{(8)}$.

Data about possible complications were also collected. The questionnaire was administered by a doctor who was blinded to patient distribution in the two groups. During follow-up; the results of the questionnaire were used to calculate the ODI, which was applied to assess clinical outcome. The response to treatment was considered binary; classified as successful if the ODI was no greater than $20 \%$ at follow-up and unsuccessful otherwise. During and after the procedures, all patients were carefully evaluated by the neuroradiologist who performed the procedure in order to recognize any complications. During phone consultation, patients were asked to report any possible late complication. Considered complications were allergic actions, high or low blood pressure induced by drugs, infections, and permanent neurologic deficits.

\section{Statistical analysis}

Data were analyzed using Statistical Program for Social Science (SPSS) version 20.0. Quantitative data were expressed as mean \pm standard deviation (SD). Qualitative data were expressed as frequency and percentage.

The following tests were done:

- A one-way analysis of variance (ANOVA) when comparing between more than two means.

- Post Hoc test was used for multiple comparisons between different variables.

- Paired sample t-test of significance was used when comparing between related samples.

- Chi-square $\left(\mathrm{X}^{2}\right)$ test of significance was used in order to compare proportions between two qualitative parameters.

- Probability (P-value):

- P-value $\leq 0.05$ was considered significant.

- P-value $\leq 0.001$ was considered as highly significant.

- P-value >0.05 was considered

\section{Results}


Abd El Shafy Haseeb et al.

Table (1): Comparison between groups according demographic data

\begin{tabular}{|l|c|c|c|c|c|}
\hline & Group I & Group II & Control & F/x2* & P \\
\hline $\begin{array}{l}\text { Age (years) } \\
\text { Mean } \pm \text { SD }\end{array}$ & $\begin{array}{c}43.63 \pm 8.28 \\
\text { Range }\end{array}$ & $\begin{array}{c}41.93 \pm 7.45 \\
28-65\end{array}$ & $\begin{array}{c}41.10 \pm 6.94 \\
23-50\end{array}$ & 0.866 & 0.424 \\
\hline $\begin{array}{l}\text { Sex [No.(\%)] } \\
\text { Male }\end{array}$ & $\begin{array}{c}17(42.5 \%) \\
\text { Female }\end{array}$ & $\begin{array}{c}17(42.5 \%) \\
23(57.5 \%)\end{array}$ & $\begin{array}{c}8(40 \%) \\
12(60 \%)\end{array}$ & $0.041^{*}$ & 0.980 \\
\hline Duration (years) & $\begin{array}{c}1.14 \pm 1.02 \\
\text { Mean } \pm \text { SD }\end{array}$ & $\begin{array}{c}1.08 \pm 0.59 \\
0.5-3\end{array}$ & $\begin{array}{c}1.34 \pm 0.78 \\
0.5-3\end{array}$ & 0.716 & 0.491 \\
Range & $0.3-6$ & 0.50 & & \\
\hline
\end{tabular}

This table shows no statistically significant difference between groups according demographic data.

\section{lumbar disc)}

The following table shows comparison between groups as regard diagnosis (level of

Table (2): Comparison between groups according diagnosis

\begin{tabular}{|l|l|l|l|}
\hline Diagnosis & Group I & Group II & Control \\
\hline LT L2-L3 & $1(2.5 \%)$ & $2(5 \%)$ & $1(5 \%)$ \\
\hline LT L3-L4 & $6(15 \%)$ & $1(2.5 \%)$ & $0(0 \%)$ \\
\hline LT L4-L5 & $12(30 \%)$ & $12(30 \%)$ & $6(30 \%)$ \\
\hline LTL5-S1 & $5(12.5 \%)$ & $3(7.5 \%)$ & $4(20 \%)$ \\
\hline RT L2-L3 & $1(2.5 \%)$ & $2(5 \%)$ & $0(0 \%)$ \\
\hline RT L3-L4 & $4(10 \%)$ & $2(5 \%)$ & $3(15 \%)$ \\
\hline RT L4-L5 & $15(37.5 \%)$ & $11(27.5 \%)$ & $5(25 \%)$ \\
\hline RT L5-S1 & $9(22.5 \%)$ & $8(20 \%)$ & $4(20 \%)$ \\
\hline Chi-square & 22.681 & & \\
\hline p-value & 0.168 & & \\
\hline
\end{tabular}

This table shows no statistically significant difference between groups according diagnosis.

The following table shows comparison between groups as regard past history.

Table (3): Comparison between groups according past history

\begin{tabular}{|c|c|c|c|c|c|c|c|c|}
\hline \multirow[b]{2}{*}{$\begin{array}{l}\text { Past } \\
\text { historv }\end{array}$} & \multirow[b]{2}{*}{ No. } & \multirow[b]{2}{*}{$\%$} & \multirow[b]{2}{*}{ No. } & \multirow[b]{2}{*}{$\%$} & \multirow[b]{2}{*}{ No. } & \multirow[b]{2}{*}{$\%$} & \multicolumn{2}{|c|}{$\begin{array}{l}\text { Chi-square } \\
\text { test }\end{array}$} \\
\hline & & & & & & & $\mathbf{x} 2$ & p- value \\
\hline $\mathrm{HTN}$ & 18 & $45.0 \%$ & 15 & $37.5 \%$ & 7 & $35.0 \%$ & 0.729 & 0.694 \\
\hline $\mathrm{DM}$ & 2 & $5.0 \%$ & 2 & $5.0 \%$ & 0 & $0.0 \%$ & 9.043 & $0.040 *$ \\
\hline & 13 & $32.5 \%$ & 11 & $27.5 \%$ & 3 & $15.0 \%$ & 2.080 & 0.353 \\
\hline & 8 & $20.0 \%$ & 4 & $10.0 \%$ & 2 & $10.0 \%$ & 1.993 & 0.369 \\
\hline
\end{tabular}

Statistically significant differences are marked by $(*)$

This table shows statistically significant difference according DM between groups

$\mathrm{p}-$ value $=0.040$, the rest have insignificant 
Comparative Study between Treatment of Lumbar Disc...

The following table shows comparison between groups as regard symptoms

Table (4): Comparison between groups according symptoms

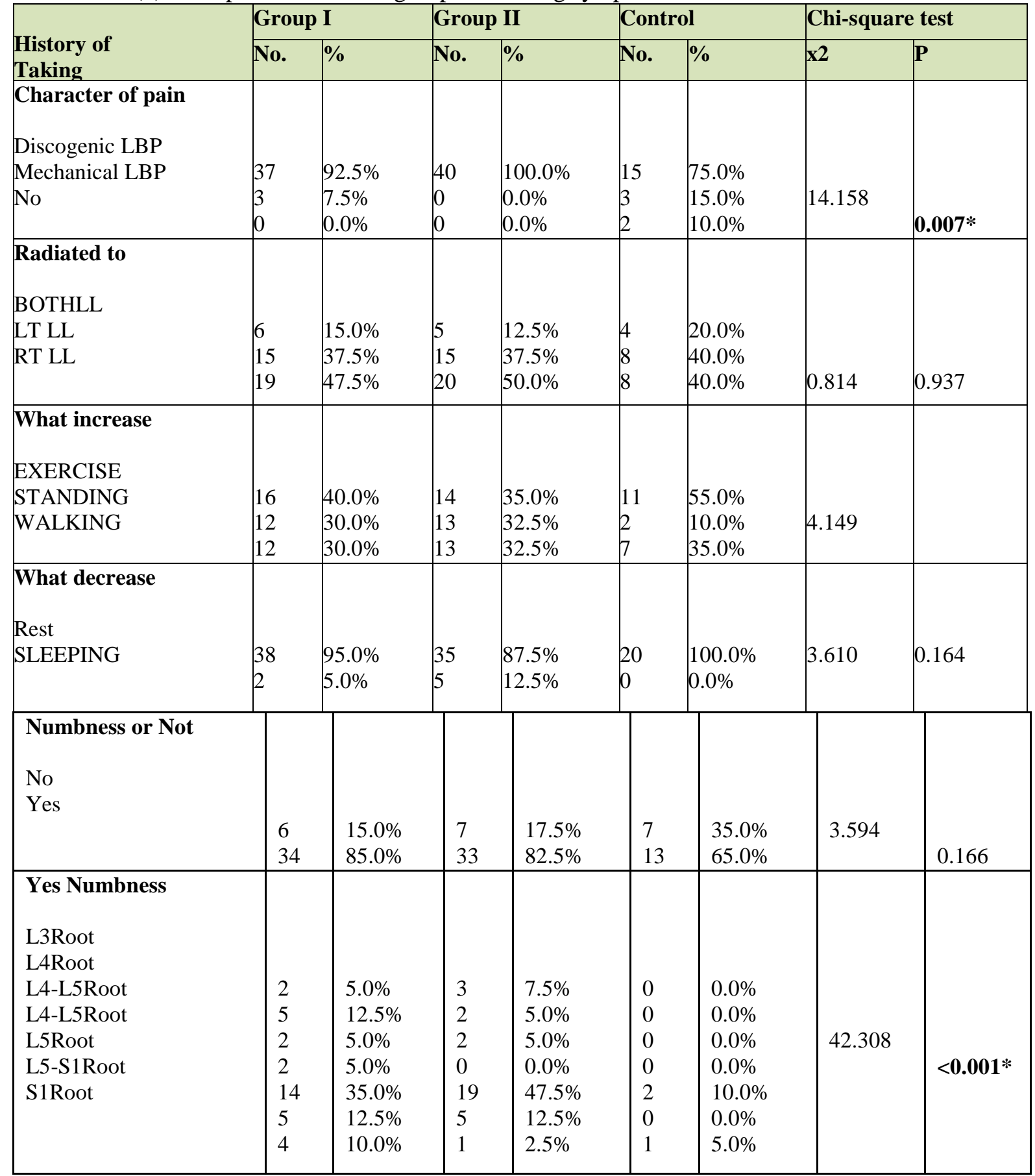

Statistically significant differences are marked by $(*)$

This table shows statistically significant difference between groups according character of pain $(\mathrm{p}$-value $=0.007)$ and numbness $(\mathrm{p}$-value $=0.001)$, the rest have insignificant correlation.

The following table shows comparison between groups as regard neurological examination. 
Abd El Shafy Haseeb et al.

Table (5): Comparison between groups according neurological examination

\begin{tabular}{|c|c|c|c|c|c|c|c|c|}
\hline \multirow{2}{*}{$\begin{array}{l}\text { Neurological } \\
\text { examination }\end{array}$} & \multicolumn{2}{|c|}{ Group I } & \multicolumn{2}{|c|}{ Group II } & \multicolumn{2}{|c|}{ Control } & \multicolumn{2}{|c|}{ Chi-square test } \\
\hline & No. & $\%$ & No. & $\%$ & No. & $\%$ & $\mathbf{x 2}$ & p-value \\
\hline $\begin{array}{l}\text { Motor } \\
\text { Abnormal } \\
\text { Normal }\end{array}$ & $\begin{array}{l}1 \\
39\end{array}$ & $\begin{array}{l}2.5 \% \\
97.5 \%\end{array}$ & $\begin{array}{l}1 \\
39\end{array}$ & $\begin{array}{l}2.5 \% \\
97.5 \%\end{array}$ & $\begin{array}{l}2 \\
18\end{array}$ & $\begin{array}{l}10.0 \% \\
90.0 \%\end{array}$ & 2.344 & 0.310 \\
\hline $\begin{array}{l}\text { Sensory } \\
\text { Abnormal } \\
\text { Normal }\end{array}$ & $\begin{array}{l}1 \\
39 \\
\end{array}$ & $\begin{array}{l}2.5 \% \\
97.5 \%\end{array}$ & $\begin{array}{l}0 \\
40 \\
\end{array}$ & $\begin{array}{l}0.0 \% \\
100.0 \%\end{array}$ & $\begin{array}{c}7 \\
13 \\
\end{array}$ & $\begin{array}{l}35.0 \% \\
65.0 \% \\
\end{array}$ & 24.932 & $<0.001 *$ \\
\hline $\begin{array}{l}\text { Reflextiones } \\
\text { Abnormal } \\
\text { Normal }\end{array}$ & $\begin{array}{l}8 \\
32\end{array}$ & $\begin{array}{l}20.0 \% \\
80.0 \%\end{array}$ & $\begin{array}{l}5 \\
35\end{array}$ & $\begin{array}{l}12.5 \% \\
87.5 \%\end{array}$ & $\begin{array}{l}7 \\
13\end{array}$ & $\begin{array}{l}35.0 \% \\
65.0 \%\end{array}$ & 4.219 & 0.121 \\
\hline
\end{tabular}

Statistically significant differences are markedby $(*)$

This table shows highly statistically significant difference between groups according sensory affection $\mathrm{p}$ value $<0.001$, the rest have in significant correlation. The following table shows comparison between groups as regard radiological examination.

Table (6): Comparison between groups according radiological examination

\begin{tabular}{|l|l|l|l|l|l|l|l|l|}
\hline \multirow{2}{*}{ Radiological examination } & \multicolumn{2}{|l|}{ GroupI } & \multicolumn{2}{l|}{ GroupII } & \multicolumn{2}{l|}{ Control } & \multicolumn{2}{l|}{$\begin{array}{l}\text { Chi-square } \\
\text { test }\end{array}$} \\
\cline { 2 - 9 } & No. & $\%$ & No. & $\%$ & No. & $\%$ & x2 & P \\
\hline Plainx-ray lumberspine & & & & & & & & \\
Abnormal & 18 & $45.0 \%$ & 11 & $27.5 \%$ & 3 & $15.0 \%$ & 6.135 & \multirow{2}{*}{.047* } \\
\hline MRIIlumber spine(Disc) & 22 & $55.0 \%$ & 29 & $72.5 \%$ & 17 & $85.0 \%$ & & \\
L2-L3 & 4 & $10.0 \%$ & 4 & $10.0 \%$ & 1 & $5.0 \%$ & 3.173 & 0.368 \\
L4-L5 & 11 & $27.5 \%$ & 4 & $10.0 \%$ & 4 & $20.0 \%$ & & \\
L5-S1 & 29 & $72.5 \%$ & 29 & $72.5 \%$ & 10 & $50.0 \%$ & & \\
\hline
\end{tabular}

This table shows statistically significant difference between groups according plain $\mathrm{x}$-ray lumber spine. 
Comparative Study between Treatment of Lumbar Disc...

Table (7): Difference between before injection and other category according Oswestry Disability Index and disability percent in group I.

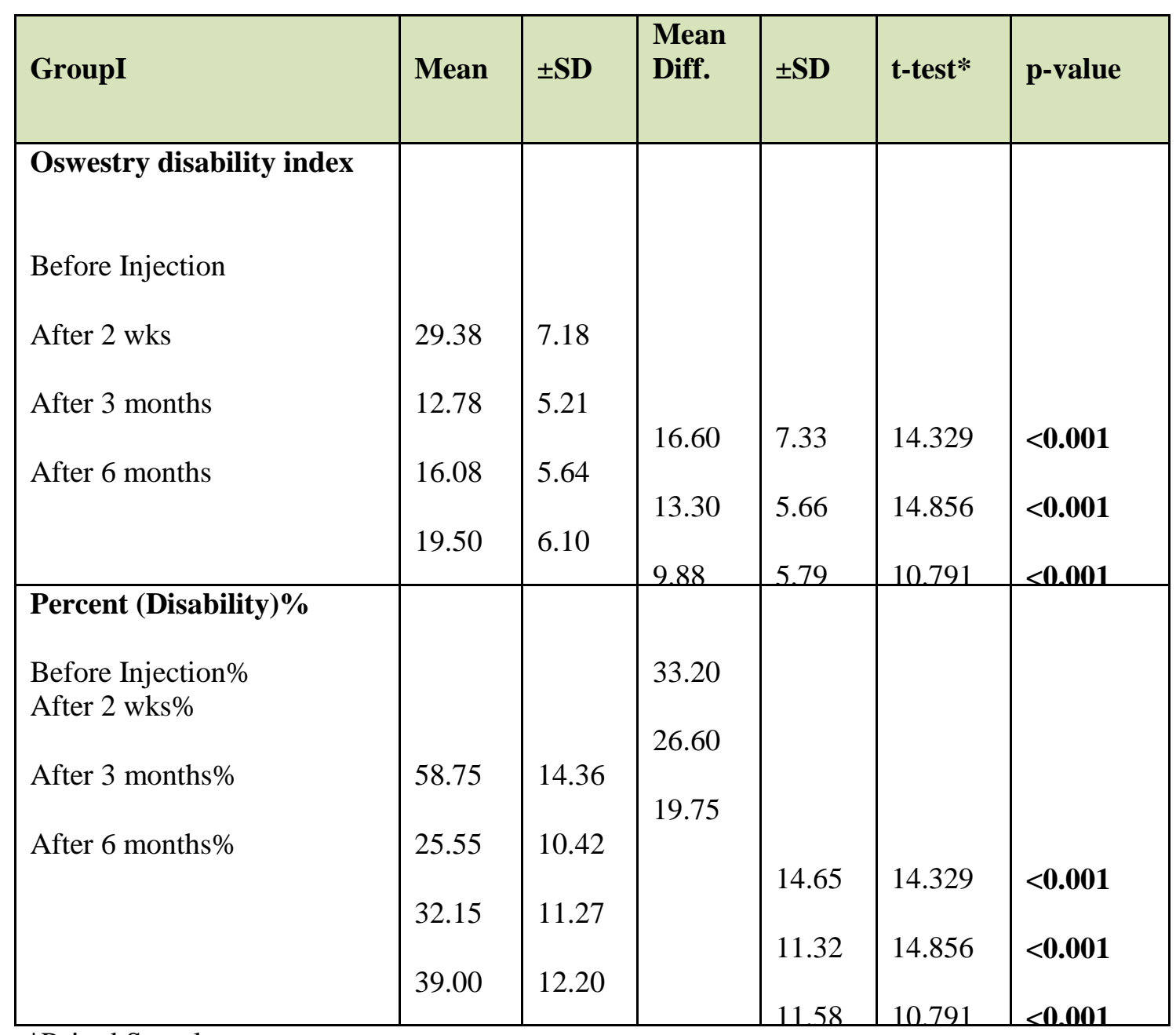

*Paired Sample t-test

This table shows highly statistically significant difference between before injection and after injection according Oswestry disability index and disability percent in group I. 
Abd El Shafy Haseeb et al.

Table (8): Difference between before injection and after injection according ODI and disability percent $\%$ in group II

\begin{tabular}{|c|c|c|c|c|c|c|}
\hline GroupII & Mean & \pm SD & $\begin{array}{l}\text { Mean } \\
\text { Diff. }\end{array}$ & $\pm \mathrm{SD}$ & t-test & $\begin{array}{l}\text { p- } \\
\text { value }\end{array}$ \\
\hline $\begin{array}{l}\text { Oswestry Disability } \\
\text { Index } \\
\text { Before Injection } \\
\text { After } 2 \mathrm{wks} \\
\text { After } 3 \text { months } \\
\text { After } 6 \text { months }\end{array}$ & $\begin{array}{l}34.38 \\
13.98 \\
15.43 \\
19.65\end{array}$ & $\begin{array}{l}12.24 \\
10.37 \\
6.91 \\
6.81\end{array}$ & $\begin{array}{l}20.40 \\
18.95 \\
14.73\end{array}$ & $\begin{array}{l}9.66 \\
8.55 \\
9.60\end{array}$ & $\begin{array}{l}13.363 \\
14.025 \\
9699\end{array}$ & $\begin{array}{l}<0.001 \\
<0.001 \\
<0001\end{array}$ \\
\hline $\begin{array}{l}\text { Percent (Disability)\% } \\
\text { Before Injection \% } \\
\text { After } 2 \text { wks } \% \\
\text { After } 3 \text { months\% } \\
\text { After } 6 \text { months\% }\end{array}$ & $\begin{array}{l}68.75 \\
27.95 \\
30.85 \\
39.30\end{array}$ & $\begin{array}{l}24.48 \\
20.75 \\
13.81 \\
13.61\end{array}$ & $\begin{array}{l}40.80 \\
37.90 \\
29.45\end{array}$ & $\begin{array}{l}19.31 \\
17.09 \\
19.20\end{array}$ & $\begin{array}{l}13.363 \\
14.025 \\
9.699\end{array}$ & $\begin{array}{l}<0.001 \\
<0.001 \\
<0.001\end{array}$ \\
\hline
\end{tabular}

This table shows highly statistically significant difference between before injection and after injection according ODI and disability percent $\%$ in group II. 
Table (9): Difference between before injection and after injection according Oswestry Disability Index and disability percent $\%$ in control.

\begin{tabular}{|c|c|c|c|c|c|c|}
\hline Control & Mean & \pm SD & $\begin{array}{l}\text { Mean } \\
\text { Diff. }\end{array}$ & \pm SD & t-test & p-value \\
\hline \multicolumn{7}{|c|}{$\begin{array}{l}\text { Oswestry Disability } \\
\text { Index }\end{array}$} \\
\hline Before Injection & 29.20 & 9.54 & 3.10 & 3.717 & 0.196 & 0.058 \\
\hline After 2 wks & 26.10 & 8.28 & 2.10 & 3.8115 & 0.130 & 0.088 \\
\hline After 3 months & 27.10 & 8.26 & & & & \\
\hline \multicolumn{7}{|c|}{ Percent (Disability)\% } \\
\hline Before Injection $\%$ & 58.40 & 19.08 & & & & \\
\hline After 2 wks $\%$ & 52.20 & 16.55 & & & & \\
\hline After 3 months $\%$ & 54.20 & 16.53 & 4.20 & $1 .+2 J$ & 0.130 & 0.000 \\
\hline
\end{tabular}

This table shows no statistically significant difference between before injection and after injection according Oswestry disability index and disability percent\% in controls.

Table (10): Comparison between groups according to complications

\begin{tabular}{|l|c|c|c|c|c|c|}
\hline \multirow{2}{*}{ Complications } & \multicolumn{2}{|c|}{ Group I } & \multicolumn{2}{c|}{ Group II } & \multicolumn{2}{c|}{ Control } \\
\cline { 2 - 8 } & No. & $\%$ & No. & $\%$ & No. & $\%$ \\
\hline Facial Flush & 3 & $7.5 \%$ & 2 & $5.0 \%$ & 0 & $0.0 \%$ \\
\hline $\begin{array}{l}\text { Increased blood } \\
\text { pressure }\end{array}$ & 2 & $5.0 \%$ & 0 & $0.0 \%$ & 0 & $0.0 \%$ \\
\hline Local Redness & 0 & $0.0 \%$ & 1 & $2.5 \%$ & 0 & $0.0 \%$ \\
\hline Minor Bleeding & 0 & $0.0 \%$ & 2 & $5.0 \%$ & 0 & $0.0 \%$ \\
\hline Nausea & 1 & $2.5 \%$ & 0 & $0.0 \%$ & 0 & $0.0 \%$ \\
\hline Numbness & 3 & $7.5 \%$ & 3 & $7.5 .0 \%$ & 0 & $0.0 \%$ \\
\hline Pain & 2 & $5.0 \%$ & 3 & $7.5 .0 \%$ & 3 & $15.0 \%$ \\
\hline $\begin{array}{l}\text { Increased blood } \\
\text { sugar }\end{array}$ & 0 & $0.0 \%$ & 2 & $5.0 \%$ & 0 & $0.0 \%$ \\
\hline Local Swelling & 0 & $0.0 \%$ & 1 & $2.5 \%$ & 0 & $0.0 \%$ \\
\hline Vasovagal & 0 & $0.0 \%$ & 5 & $12.5 \%$ & 0 & $0.0 \%$ \\
\hline
\end{tabular}




\begin{tabular}{|l|r|c|c|c|c|c|}
\hline \multirow{2}{*}{ Complications } & \multicolumn{2}{|c|}{ Group I } & \multicolumn{2}{c|}{ Group II } & \multicolumn{2}{c|}{ Control } \\
\cline { 2 - 7 } & No. & $\%$ & No. & $\%$ & No. & $\%$ \\
\hline Complications & 11 & $27.5 \%$ & 19 & $47.5 \%$ & 3 & $15.0 \%$ \\
\hline No Complications & 29 & $72.5 \%$ & 21 & $52.5 \%$ & 17 & $85.0 \%$ \\
\hline Chi-square test & \multicolumn{7}{|c|}{9.581} \\
\hline p-value & \multicolumn{7}{|c|}{0.137} \\
\hline
\end{tabular}

- From this table 11 patients $(27.5 \%)$ in group I, 19 patients $(47.5 \%)$ in group IIand3 patients (15\%) In control group reported side effects related to the injection.

- 3 patients $(7.5 \%)$ had facial flush in group I while 2 patients $(5.0 \%)$ in group II and no one in control group.

- 2 patients (5.0\%) in group I experienced increased blood pressure.

- 1 patient in group II had local redness at site of injection

- 2 patients (5.0\%) in group II had minor bleeding at site of injection.

- 1 patient in group I experienced nausea.

- 3 patients (7.5\%) in both group I and group II had numbness.

- 2 patients (5.0\%) in group I and 3 patients in both group II and control experienced pain at site of injection

\section{Discussion}

Low back pain (LBP) is one of the most common disorders with prominent effects on patients' clinical status, socioeconomic situation, and public health. Its one-year prevalence is estimated to be $22 \%-65 \%$, besides $80 \%$ of adults are involved with mild to severe LBP at some points in their lives ${ }^{(9)}$.

In $5 \%$ to $15 \%$ of cases, the origin of pain was attributed to degenerative joints and disk lesions. Disk or nucleus pulposus herniation is one of the most important disk lesions. Various therapeutic options have been proposed for the treatment of disk herniation (DH), including conservative treatments, less invasive methods (steroid injection, chemonucleosis, intrathecal decompression, laser and annuloplasty), and surgical methods. Non-invasive conservative methods are the first choice in many cases, but failed treatments pop up other less invasive options ${ }^{(\mathbf{1 0})}$.
Disk herniation induces mechanical compression in addition to biochemical, immunologic and inflammatory changes in the vicinity of disk area. Intra discal injection is a minimally invasive and inexpensive procedure that induces disk shrinkage and alleviates nerve root inflammation. This procedure is used in many countries, including European countries. In this procedure, a mixture of ozone and oxygen is injected into the disk (11).

The aim of the present work (primary outcome) is to determine if $\mathrm{O} 2-\mathrm{O} 3$ therapy is a useful treatment for lumbar disk herniation that has failed to respond to conservative management and has a significant cumulative effect.

One hundred patients were included for this study,(42 men, 58 women; age range, 23-65 years) were included for this study, selected from Agouza Rheumatology and Rehabilitation center all cases were diagnosed as lumbar disk herniation and radicular pain by Radiologic findings showing disc herniation based on magnetic resonance imaging (MRI) and Electrodiagnostic studies; for lumbar radiculopathy evaluation.

In our study, in group I, we administered an intradiscal and transforaminal steroid and an anesthetic.

The functional status of the patients according to Oswestry disability index (ODI), showed a significant improvement in the follow-up periods compared with the period before the intervention. The mean \pm SD of ODI was $29.38 \pm 2.1$ before the intervention. There was more than $50 \%$ reduction in ODI after two weeks (the mean of 12.3) ( $\mathrm{P}<0.001)$ and it was almost sustained till sixth months after the intervention. 
On comparison between group I and control; the functional status of the patients according to Oswestry disability index (ODI), showed significant improvement in group I compared with the control group two weeks after the intervention and it was almost sustained till sixth months after the intervention.

This may be explained by disc herniation and radiculitis are based on a pathophysiologic explanation of inflammatory pathology ${ }^{(\mathbf{1 2})}$, disc herniation, annular tear, degenerative disc disease) results in the release of phospholipase A2 from the nucleus pulposus into the epidural space ${ }^{(13)}$. Phospholipase A2, an enzyme found in high concentrations in disc material, is responsible for initiating the arachidonic acid cascade, which results in the production of prostaglandins, leukotriens, and other mediators of inflammation (14). So, epidural and intradiscal steroids have been recommended to be effective in disc herniation and radiculitis secondary to their anti inflammatory profiles, Emerging evidence shows that local anesthetics with or without steroids are equally effective in many settings ${ }^{(\mathbf{1 5})}$.

This may be explained by the dilution of inflammatory mediators by the volume on injected material (injectate) around the affected nerve root. This may account for the beneficial effects of epidural normal saline or local anesthetics alone

The previous studies support our study these studies include

Abdi et al. ${ }^{(16)}$ showed that the evidence of lumbar transforaminal epidural steroid injections for lumbar nerve root pain was strong for short-term ( $<6$ weeks) and moderate for long-term improvement $(>6$ weeks). However, they showed limited evidence for transforaminal injections for lumbar radicular pain in post surgery syndrome.

Manchikanti et al. ${ }^{(15)}$ also used the same evidence in the development of interventional pain management guidelines.

This randomized, active control trial of 120 patients treated with either transforaminal with local anesthetic or transforaminal local anesthetic with steroids with persistent low back and lower extremity pain secondary to disc herniation and radiculitis showed significant improvement in all parameters in both groups. At the end of 2 years, significant improvement was seen in $65 \%$ of patients administered local anesthetics alone and $57 \%$ of patients administered local anesthetic and steroid when all participants were included ${ }^{(\mathbf{1 2})}$.

In our series, in group II; we administered an intradiscal and transforaminal steroid and an anesthetic with the addition of an $\mathrm{O} 2-\mathrm{O} 3$ mixture, the functional status of the patients according to Oswestry disability index (ODI), showed a significant improvement in the follow-up period compared with the period before the intervention. The mean \pm SD of ODI was $29.38 \pm 2.1$ before the intervention. There was more than $50 \%$ reduction in ODI after two weeks (the mean of 12.78) (P < 0.001 )and it was almost sustained till sixth months after the intervention.

This may be explained by periganglionic and intradiscal injections of O2-O3 have been proposed since the late 1990s as a treatment for lumbar disk herniation ${ }^{(17)}$.

Ozone is an unstable form of oxygen that, in water, reacts with organic molecules containing double or triple bonds: Ozone causes an oxide reduction called ozonolysis. This reaction involves mainly molecules for which ozone has affinity ${ }^{(18)}$.

Intradiscal O2-O3 mixture injection produces a chemodiscolysis, with ozonolysis of nucleus pulposus proteoglycans, loss of water, and dehydration. Progressive degeneration with fibrous replacement occurs followed, finally, by disk shrinkage. In this way, chemodiscolysis leads to loss of disk volume and direct reduction of root compression. Chemodiscolysis has been shown experimentally in rabbit and human disks, with histopathologic evidence of dehydration of the fibrillary matrix of the nucleus pulposus, vacuole formation, and collagen fragmentation ${ }^{(\mathbf{1 9})}$.

In our study we observed that 2 weeks, 3 Months and 6 months s after the procedure, the difference in success rate between group I and group II was not significant.

Many previous studies support our study results Bonetti et $\boldsymbol{a l}^{(\mathbf{( 2 0 )}}$ which 
revealed that there was no significant statistical difference between treatment of injection of oxygen-ozone combined with steroid and steroid only in the 6 and 12 months follow-up.

However, multiple other reviews like Gallucci et al..$^{(21)}$ revealed that the combined injection of O2-O3, a steroid, and an anesthetic at the intradiscal and intraforaminal levels should be considered more effective than a simple steroid and anesthetic injection. The injection of O2-O3 is the only difference between the two treatments we compared; therefore, the better outcome of group B patients should be due to the pharmacologic actions of $\mathrm{O} 2$ O3.

Therefore, in comparison to conventional steroid injections, O2-O3 therapy appears to be a more effective treatment. The 6-month success rate of group B patients is similar to that obtained with other percutaneous intradiscal interventions (22). Intradiscal and intraforaminal $\mathrm{O} 2-\mathrm{O} 3$ injections are less invasive for many reasons, such as a narrower needle and absence of probes and of toxicity. O2-O3 therapy is also costeffective, because it can be performed on an outpatient basis and thus has favorable implications for cost, as does the equipment needed for the procedure. In our experience, there were no complications, which helped confirm that $\mathrm{O} 2-\mathrm{O} 3$ chemodiscolysis is a safe procedure ${ }^{(23)}$.

\section{Limitation of the study}

The limitations of this study are lack of long-term following-up. Further study is necessary to evaluate the long-term outcome of ozone nucleolysis therapy. Another limitation of the study is the lack of imaging follow-up studies during the period of conservative treatment. This would have been beneficial and would have worked as an internal control to validate the results of the study.

\section{Conclu}

sion

In our study, oxygen-ozone nucleolysis combined with steroid provides excellent pain relief in most herniated disc patients who failed to respond to conservative therapy and there was no significant statistical difference between treatment of injection of oxygen ozone combined with steroid and steroid only in2 weeks, three months and6 months follow-up. Therefore, O2-O3 seems to play a role in pain relief, and we suggest the administration of the O2-O3 mixture combined with transforaminal steroid injection as a first-choice treatment before recourse to surgery or when surgery is not possible.

\section{Recommenda tions}

We regard the present study as a step in quantitative evaluation of ozone effects on volume of treated herniated vertebral disks. Further studies are needed to evaluate the exact impact of disc shrinkage on pain reduction after intradiscal and periganglionic ozone-oxygen injection combined with periganglionic administration of corticosteroid and anesthetic agents. In addition, the influence of ozoneinduced disc volume changes on lumbar spine stability has to be clarified.

\section{References}

1. Korhonen T, Karppinen J, Paimela L et al. (2006): The treatment of disc herniation-induced sciatica with infliximab: one-year follow-up results of FIRST II, a randomized controlled trial. Spine, 31(24): 2759-2766.

2. Lehnert T, Naguib N, Wutzler S et al. (2012): Analysis of disk volume before and after CT-guided intradiscal and periganglionic ozone-oxygen injection for the treatment of lumbar disk herniation. Journal of Vascular and Interventional Radiology, 23(11): 1430-1436.

3. Topuz K, Eroglu A, Simsek H et al. (2016): Demographical Aspects of Central Large Lumbar Disc Herniation. Turkish Neurosurgery, 26 (1): 111-118.

4. Oder B, Loewe M, Reisegger $M$ et al. (2008): CT-guided ozone/steroid therapy for the treatment of degenerative spinal disease - effect of age, gender, disc pathology and multisegmental changes. Neuroradiology, 50(9): 777-785.

5. Seyam O, Smith $\mathrm{N}$, Reid I et al. (2018): Clinical utility of ozone therapy for musculoskeletal disorders. Medical Gas Research, 8(3): 103-108.

6. Ezeldin M, Leonardi M, Princiotta 
C et al. (2018): Percutaneous ozone nucleolysis for lumbar disc herniation. Neuroradiology, 60(11): 1231-1241.

7. Tumialán LM, Madhavan K, Godzik J et al. (2018): The history of and controversy over Kambin's Triangle: A historical analysis of the lumbar transforaminal corridor for endoscopic and surgical approaches. World Neurosurg, 8:1878-8750.

8. Narotam PK (2016): The Utility of Health Care Performance Indicators in Evaluating Low Back Surgery. Walden University. https://scholarworks.waldenu.edu/cgi /viewcontent.cgi?referer=https://ww w.google.com/\&httpsredir=1\&article $=3428 \&$ context $=$ dissertations

9. Weiner BK and Patel R (2008): The accuracy of MRI in the detection of lumbar disc containment. Journal of Orthopaedic Surgery and Research, 3(1): 46-62.

10. Raj PP (2008): Intervertebral disc: anatomy physiology pathophysiology-treatment. Pain Practice, 8(1): 18-44.

11. Martín NA and García GR (2016): Ozone Therapy for Patient poisoned by Carbon Monoxide. Revista Española de Ozonoterapia, 6 (1): 165186.

12. Manchikanti L, Staats P, Nampiaparampil DE et al. (2015): What is the role of epidural injections in the treatment of lumbar discogenic pain: a systematic review of comparative analysis with fusion. The Korean Journal of Pain, 28(2): 75-87.

13. Rydevik B, Brown MD and Lundborg G (1984): Pathoanatomy and pathophysiology of nerve root compression. Spine, 9(1):7-15.

14. Saal J, Franson R, Dobrow $R$ et al. (1990): High levels of inflammatory phospholipase A2 activity in lumbar disc herniations. Spine, 15(7): 674678.

15. Manchikanti L, Knezevic NK, Boswell M et al. (2016): Epidural injections for lumbar radiculopathy and spinal stenosis: a comparative systematic review and meta-analysis. Pain Physician, 19: 365-410.
16. Abdi S, Datta S, Trescot A et al. (2007): Epidural steroids in the management of chronic spinal pain: A systematic review. Pain Physician, 10:185-212.

17. Yang, X.; Zhang, Q.; Hao, X.; Guo, $X$. and Wang, L. (2016): Spontaneous regression of herniated lumbar discs: Report of one illustrative case and review of the literature. Clinical Neurology and Neurosurgery, 143: 86-89.

18. Lotz JC and Ulrich JA (2006): Innervation, inflammation, and hypermobility may characterize pathologic disc degeneration: review of animal model data. JBJS., 88: 7682.

19. Andreula C, Muto M, and Leonardi $M$ (2004): Interventional spinal procedures. European Journal of Radiology, 50(2): 112-119.

20. Bonetti M, Fontana A, Cotticelli B et al. (2005): Intraforaminal $\mathrm{O}(2)-$ $\mathrm{O}(3)$ versus periradicular steroidal infiltrations in lower back pain: Randomized controlled study. Am J Neuroradiol., 26:996-1000.

21. Gallucci M, Limbucci N, Zugaro L et al. (2007): Sciatica: Treatment with intradiscal and intraforaminal injections of steroid and oxygenozone versus steroid only. Radiology, 242:907-913.

22. Chou R, Fu R, Carrino J et al. (2009): Imaging strategies for lowback pain: systematic review and meta-analysis. The Lancet, 373(9662): 463-472.

23. Alexandre A, Buric $\mathbf{J}$, Paradiso $\mathbf{R}$ et al. (2002): Intradiscal injection of $\mathrm{O} 2-$ $\mathrm{O} 3$ to treat lumbar disc herniations. Rivista Italiana di OssigenoOzonoterapia, 1: 165-169. 